Original article

\title{
Assessing habitat differentiation between coexisting species: The role of spatial scale
}

\author{
Ricardo Pita ${ }^{\mathrm{a}, \mathrm{b}, *}$, António Mira ${ }^{\mathrm{a}, \mathrm{b}}$, Pedro Beja ${ }^{\mathrm{c}}$ \\ ${ }^{a}$ Unidade de Biologia da Conservação, Universidade de Évora - Núcleo da Mitra, Apartado 94, 7002-554 Évora, Portugal \\ ${ }^{\mathrm{b}}$ Grupo de Ecossistemas e Paisagens Mediterrânicas - Instituto de Ciências Agrárias e Ambientais Mediterrânicas, Universidade de Évora - Núcleo da Mitra, \\ Apartado 94, 7002-554 Évora, Portugal

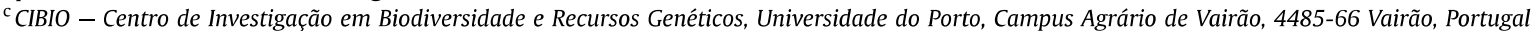

\section{A R T I C L E I N F O}

\section{Article history:}

Received 9 July 2010

Accepted 10 January 2011

Available online 5 February 2011

\section{Keywords:}

Habitat selection

Mediterranean farmland

Niche overlap

Species coexistence

Voles

\begin{abstract}
A B S T R A C T
Although the importance of spatial scale for understanding habitat selection patterns and processes has long been recognized, little is known about its impact on the identification of habitat differentiation between sympatric species, despite its likely utility in assessing niche partitioning and thus explaining species coexistence. Here we used radio-telemetry data to examine seasonal habitat selection and differentiation by Cabrera $(n=28)$ and water voles $(n=29)$ within habitat patches in a highly fragmented landscape, across spatial extents and resolutions. Habitat selection was found for both species at the home-range and core-area scales, tending to be strongest for water and Cabrera voles at coarse and fine spatial resolutions, respectively. Water voles showed higher preference for humid sedge/rush and reed habitats across seasons and spatial scales. Cabrera voles consistently selected tall grass and shrub habitats during the wet season, whereas dry season preference was higher for sedge/rush and tall grass at fine and coarse spatial resolutions, respectively. Niche overlap was highest during the dry season, lowest at the core-area scale, and increased with spatial resolution. These patterns likely reflected the fine-scale, seasonal habitat preferences of the Cabrera vole, which during the dry season increased the use of small sedge/rush patches embedded in larger tall grass meadows, thereby bringing it in closer contact to the humid habitats selected at coarse spatial resolutions by the water vole throughout the year. Overall, this study suggests that spatial scale may critically influence the perception of habitat differentiation between coexisting species.
\end{abstract}

(c) 2011 Elsevier Masson SAS. All rights reserved.

\section{Introduction}

Analysing the range of spatial scales at which habitat selection by animals operates has important implications for understanding how species perceive and respond to their environment (Mayor et al., 2007; Schaefer and Mayor, 2007), and how they discriminate between habitats of different quality (Chalfoun and Martin, 2007; Bellier et al., 2010). Multi-scaled habitat selection studies provide detailed characterization of species habitat profiles (Boyce, 2006; Mayor et al., 2009) by including multiple hierarchical orders of selection (e.g. Rettie and Messier, 2000; Beasley et al., 2007), and multiple spatial resolutions of habitat resources across varying

\footnotetext{
* Corresponding author. Grupo de Ecossistemas e Paisagens Mediterrânicas Instituto de Ciências Agrárias e Ambientais Mediterrânicas, Universidade de Évora - Núcleo da Mitra, Apartado 94, 7002-554 Évora, Portugal. Tel.: +351 917802087 . fax: +351217991119 .

E-mail address: ricardo.pita@gmail.com (R. Pita).
}

domains and extents of analysis (e.g. Thompson and McGarigal, 2002; Wheatley, 2010). In the one hand, hierarchical orders reflect distinct behavioural processes operating at nested spatial scales, e.g. from the selection of a home-range within an area, to the selection of patches of resources within a home-range (Johnson, 1980). On the other hand, the domain of analysis and spatial resolution distinguish broad-level from fine-scale habitat selection, thus reflecting responses to multiple scales of habitat patchiness and patch structure (Kotliar and Wiens, 1990; Thompson and McGarigal, 2002). There is increasing empirical evidence that the magnitude and direction of habitat preferences by species may change across hierarchical orders and measures of habitat patchiness (e.g. Thompson and McGarigal, 2002; Beasley et al., 2007), thereby requiring that habitat selection studies should be routinely conducted at multiple spatial scales (Mayor et al., 2009).

Although the utility of multi-scaled habitat selection studies is now widely recognized, this approach has rarely been used to assess differentiation among interacting species sharing the same 